\title{
ESTUDO DOS LINFÓCITOS CIRCULANTES POR ANTICORPOS MONOCLONAIS NA MIASTENIA GRAVE
}

\author{
PAULO E. MARCHIORI * - ALBERTO J. DUARTE**- M. IZABEL A. M. BIROLLI*** \\ CRISTINA A. FIGUEIREDO*** - MILBERTO SCAFF**** \\ J. LAMARTINE DE ASSIS ****
}

\begin{abstract}
RESUMO - Os autores avaliam os linfócitos $\mathrm{T}$ (CD3, CD4, CD8, CD4/8) por anticorpos monoclonais e rosácea em 20 pacientes e linfócitos $B$ por Fab' por imunofluorescência em 9 pacientes com miastenia grave. Observam elevação significante na população de linfócito $\mathbf{B}$ e reduçāo nos linfócitos $\mathrm{T}$ totaís CD3+ por rosáceas. Nāo foram observadas modificações nas subpopulaçōes celulares com timectomia e corticosteróides.
\end{abstract}

Evaluation of circulant lymphocytes in myasthenia gravis by monoclonal antibodies.

SUMMARY - A significant decline of CD3 cell detected by rosettes and a significant increased of $B$ cell populations were observed. The total CD3+, helper CD4+ and suppressor CD8+ T-cell subsets showed no significant variation em relation to sex, age thymectomy and corticotherapy by monoclonal antibodies.

Evidèncias inunológicas na miastenia grave (MG) se expressam pela presença de auto-anticorpos 4,15. Ocorrem produção de anticorpo contra o receptor de acetilcolina (AAChR) e dificuldades na transmissão nervosa na junção neuromuscular (JNM) ${ }^{2,6}$. Esse processo é o resultado final da estimulação policlonal dos linfóticos B 2 A interação de inúmeros fatores — genético, hormonal, ambiental e estímulo antigênico - propicia modificações no microambiente do timo, com alteraçôes da barreira hemotimica. As relações timo-MG são amplas no aspecto histopatológico, imunológico e terapêutico 1,18. Ocorre maturação progressiva dos linfócitos $T$ até segregação de fenótipos de células auxiliadoras $(\mathrm{CD} 4+)$, supressoras $(\mathrm{CD} 8+)$ e totais $(\mathrm{CD} 3+)$, funcionalmente maduras 11. Há aumento das células B e Tg e redução das células T 2,11,14,19. Possivelmente ocorra modificação inicial na célula T-H (auxiliadora). A intensidade e duração de reação imune no circuito são determinadas por mensagens (interleucinas) entre os diferentes tipos celulares 6,10,16. Desequilibrios no sistema podem concorrer para o estado de doença 9-12,15,16.

Contrastando com a imunidade humoral, os resultados das pesquisas na imunidade celular na MG têm sido pobres até o momento. $O$ emprego dos anticorpos monoclonais, recentemente, abriu novas perspectivas neste campo, motivo pelo qual, utilizamos este método na avaliação das subpopulaçōes de linfócitos $T$, em 20 pacientes com $M G$.

Disciplina de Neurologia Clínica (DNC) do Departamento de Neurologia da Faculdade de Medicina da Universidade de São Paulo (FMUSP) e Laboratório de Imunogenética e Transplante Experimental (LIM 73) do Instituto dos Laboratórios de Investigação Médica (LIM) do Hospital das Clínicas (HC) da FMUSP: * Médico Assistente da DNC; ** Professor Livre Docente da Disciplina de Alergia e Imunologia da FMUSP; *** Biologista do LIM 73; **** Professor Adjunto da DNC. Trabalho financiado pelo LIM, HC, FMUSP. 


\section{VASUISTICA E METODOS}

Vinte pacientes com MG con média de idade de $\mathbf{2 8 , 8 5 \pm 9 , 9 7}$ anos (a) diagnosticados por história clínica, eletromiografia e testes imunológicos foram submetidos a determinação de subpopulaçỏes linfocitárias; duração média de doença de $6,22 \pm 5,74$ a; 10 eram do sexo feminino e 10 do masculino. Quinze foram submetidos a timectomia e 5 não foram timectomizados. Quatro usaram corticosteróides. Os valores de referéncia foram extraídos de uma amostra de 17 doadores de sangue e cada paciente foi analisado em paralelo com indivíduo controle. Todos foram analisados para subpopulaçōes de linfócitos (CD3, CD4 CD8) por anticorpo monoclonal; linfócitos totais por rosácea $\mathbf{E}$ foram analisados em 9: linfócitos $\mathbf{B}$ por $(\mathrm{Fab})_{2}$, em 9 pacientes.

Quantificação de linfócitos $T$ e $B$ - células mononucleares foram obtidas através de gradiente de Fícoll-Hypaque. A quantificacão de linfócitos $T$, $\mathbf{B}$ e subpopulaçỏes foram analisadas através de técnicas anteriormente descritas (8), Linfócito B - Células mononucleares foram tratadas com fragmento (Fab) de anticorpo de coelho anti-imunoglobulina humana (Cappell Laboratories, Cochranville, PA, USA) durante 60 minutos a $4 \circ$. Posteriormente, as células foram lavadas com solução de Hanks azida a $0,1 \%$ e enumeradas em microscópio munido com luz ultravioleta. Linfócito $\mathbf{T}$ - Células mononucleares foram tratadag com anticorpo monoclonal (CD3, CD4, CD8 - Ortho Diagnostic systems Inc, Raritan, New Jersey, USA) durante 60 minutos a 40C. Posteriormente, estas células foram lavadas e anticorpo de coelho anti-IgG de camundongo (Cappell Laboratories, Cochranville, PA, USA) foi adicionado seguindo-se nova incubaçãa por 60 minutos. A segu r estas células foram lavadas em Hanks azida a $0,1 \%$ e enumeradas em microscópio munído de luz ultravjoleta. A presença simultânea de anticorpos CD4 e CD3 na superfície celular foi realizada por comparação do número de célullas fluorescentes após a incubação individual de CD4 e CD8 e com ambos os anticorpos. Os resultados foram expressos em \% de células positivas ou em números absolutos; células $\mathrm{T}$ foram avaliadas tambén pela rosácea $\mathbf{E}$ de carneiro.

\section{RESULTADOS}

Os niveis médios de subpopulaçōes de linfócitos são observados na tabela 1 e na fikn Lĩa $l$. os pacientes miastênicos e os controles diferem quanto a (Fab' $)(z=2,46 ; a=0,05)$ e rosaceas $(z=1,66)$. As flutuações, relacionadas ao grupo controle, mostram mínimas modificações e declínio de 4,70\% nos linfócitos totais (células CD3+), 4,32\% nas células supressoras/indutoras (CD8+) e discreta elevaçāo (6.40\%) em células auxiliares (CD4+). Linfócitos B, por Fab'

\begin{tabular}{|c|c|c|c|c|c|c|}
\hline Subpopulação & $\begin{array}{c}\text { No de } \\
\text { pacientes }\end{array}$ & Média & $\begin{array}{l}\text { Desvio } \\
\text { padrão }\end{array}$ & $\begin{array}{l}\text { Signifi- } \\
\text { cância (a) }\end{array}$ & Minima & Máxima \\
\hline * CD3+ & 20 & 55,18 & 18.70 & NS & 36 & 82 \\
\hline Controle & & 57,50 & 1.76 & & & \\
\hline$* \mathrm{CD} 4+$ & 20 & 41,15 & 14,38 & NS & 27 & 64 \\
\hline Controle & & 40.00 & 5,09 & & & \\
\hline Rosácea. & 9 & 55,80 & 20,86 & $\mathbf{S}$ & 43,5 & 75 \\
\hline Controle & & 69,00 & 6,51 & & & \\
\hline $\mathrm{Fab}_{2}^{\prime}$ & 9 & 17,40 & 7,17 & $\mathbf{S}$ & 10,0 & 29,0 \\
\hline Controle & & 12.10 & 2,65 & & & \\
\hline
\end{tabular}

Tabela 1 - Avaliação de linfocitos no sangue de pacientes com miastenia grave. CD3+, celulas totais; CD4t, células muxiliadoras; CD8t, células supressoras e indutoras; *, anticorpos monoclonais; (a), teste $U$, Mann-Whitney (alfa $=0,05$ ); NS, não significrante; s, significante. 


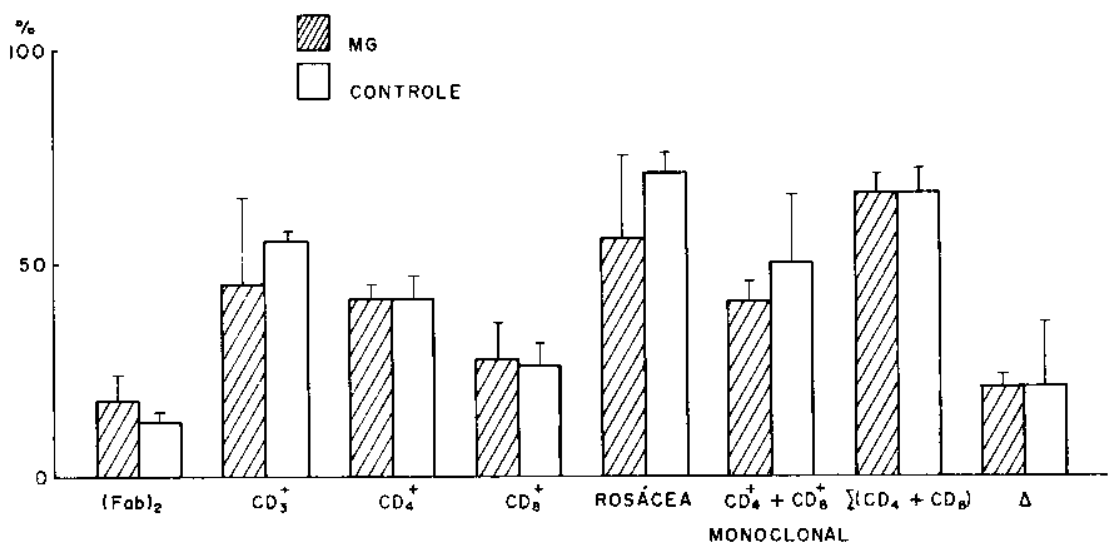

Fig. 1 - Concentraçes de subpopulacós de linfócitos na miastenia grave.

revelam aumento de $55 \%$; linfócitos totais por rosácea $\mathbf{E}$ dímínuem de $11 \%$. A concentração de células $\mathrm{CD} 4+$ e CD8+, determinada por adição dos anticorpos em conjunto é 45,94士4,20 $(49,1 \pm 15,20)$, enquanto a somatória das subpopulaçóes individualizadas é $66,77 \pm 4,16(67,25 \pm 5,73)$ (Tabela 2 ; Fig. 2). A influência da timectomia nas subpopulaçōes linfocitárias ê vista na tabela 3 e na figura 3 . Nāo houve modificações quanto a idade, sexo, duração da doença e o emprego de corticosteróides.

\section{COMENTARIOS}

Células CD3+ (linfócitos $T$ totais), avaliadas por anticorpos monoclonais, não mostraram diferenças significantes em relação ao grupo controle, contrastando com Christadoss 5, que mostrou número e função diminuidos, e Skolnik 20, que revelou CD3 diminuidos em miastênicos com idade superior a 35 anos; CD3 + determinadas por rosácea estão significativamente reduzidas na $M G$. Dessa forma acreditamos que

\begin{tabular}{|c|c|c|c|c|c|c|c|}
\hline \multirow{2}{*}{ Subpopulação } & \multirow{2}{*}{$\begin{array}{c}\mathrm{N}^{\circ} \mathrm{de} \\
\text { pacientes }\end{array}$} & \multicolumn{4}{|c|}{$\begin{aligned} \text { Frequência de subpopulações } \\
\text { de linfócitos }\end{aligned}$} & \multirow{2}{*}{$\begin{array}{l}\text { Signifi- } \\
\text { cância** }\end{array}$} & \multirow{2}{*}{$\begin{array}{l}\text { Anticorpo } \\
\text { monociona }\end{array}$} \\
\hline & & Média & padrāo & Mínima & Máxima & & \\
\hline OKT4t - OKT $8+$ & 9 & 45,94 & 4,20 & 40 & 55 & NS & associado \\
\hline Controle & & 49,10 & 15,20 & 22,5 & 60 & & \\
\hline$(\mathrm{OKT} 4++$ OKT8 +$)$ & 9 & 66,77 & 4,16 & 60 & 70,5 & NS & isolado \\
\hline Controle & & 67,25 & 5,73 & 60 & 74 & & \\
\hline Variação celular & 9 & 20,83 & 3,94 & 15,5 & 25,5 & NS & \\
\hline Controle & & 20,87 & 21,24 & 2,5 & 51,5 & & \\
\hline
\end{tabular}

Tabela 2- Linfocitos com dupla marcagão em miastenia gnave: OKT4+ - oKT8+ = células determinadas pela utiliząäo de OKT4 e OKT8 assaciadamente; (OKT4+ + OKT8+) $=$ somatória de células determinadas pelo anticorpo isoladamente; variaçáo celulas (delta), avaliaçāo na forma apresentada; **, teste de Mann-Whitney ( 1 alfa $=0,05)$; NS, näo significante. 


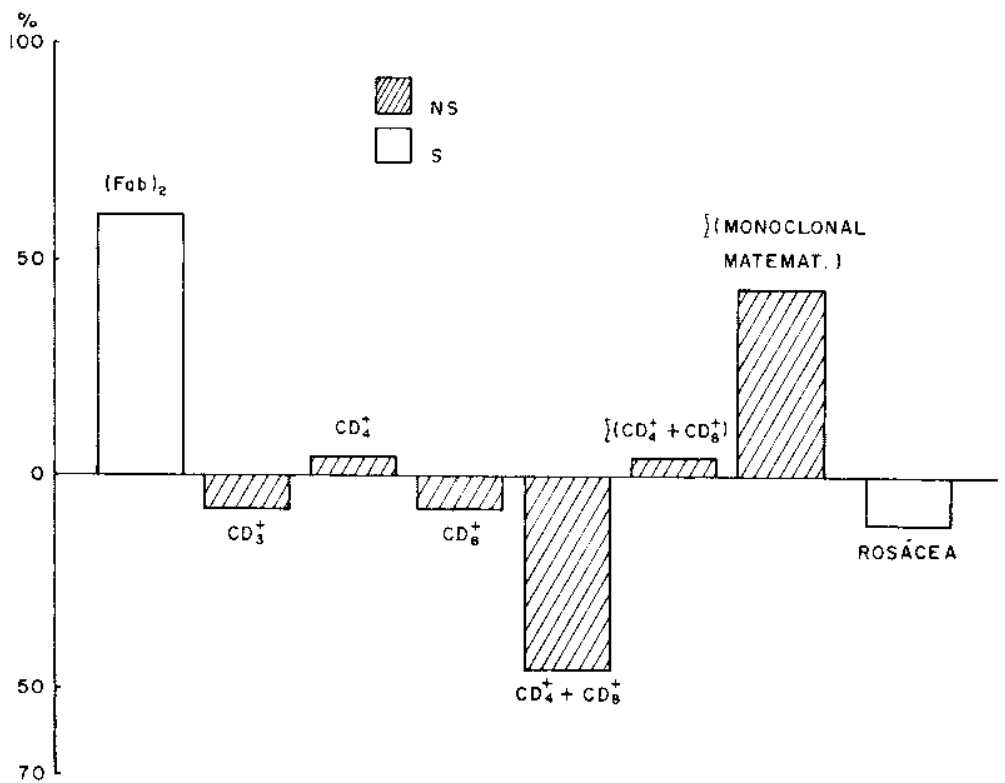

F'ig. 2 - Subpopulaçes de linfocitos na miastenia grave.

Frequência de subpopulaçôes de linfócitos

\begin{tabular}{|c|c|c|c|c|c|}
\hline \multirow{2}{*}{ Terapêutica/Subpopulação } & & & & & \multirow{2}{*}{ Significância** } \\
\hline & Média & $\begin{array}{l}\text { Desvio } \\
\text { padrão }\end{array}$ & Minima & Máxima & \\
\hline Timectomizado/OKT3+ & 58,03 & 12,53 & 29 & 82 & NS \\
\hline Controle & 58,8 & 16,10 & 36 & 81,5 & \\
\hline Timectomizado/OKT $4+$ & 44,76 & 9,84 & 27 & 64 & NS \\
\hline Controle & 41,3 & 11,80 & 22,5 & 54 & \\
\hline Timectomizado/OKT $8+$ & 28,62 & 14,05 & 16 & 76 & NS \\
\hline Controle & 25,1 & 10,66 & 12,5 & 41 & \\
\hline Timectonizado/OKT $4 / 8$ & 1,87 & 0,66 & 1,3 & 4,0 & NS \\
\hline Controle & 1,83 & 0,98 & 1,1 & 3,4 & \\
\hline
\end{tabular}

Tabela 3 - Influência da timectomia nas subpopuląōes linfocitarias na miastenia grave. OKT3, celulas totais; OKT4+, células auxiliadoras; OKT8+, células supressoras e indutoras: **, teste $U$, Mann-Whitney (alfa $a=0,05) ; N S$, näo significante.

a ambiguidade de comportamento da populaçăo dos linfócitos totais por técnicas metodológicas diferentes pode sugerir que os linfócitos determinados por rosácea estejam comprometidos na MG.

As células auxiliadoras (CD4t) e supressoras (CD8+) não se comportaram de forma diferente ao grupo controle, embora Haynes ${ }^{9}$ e Skolnik 20 mostrassem subpopulação $\mathrm{CD} 4+$ reduzida, que se normalizou após a timectomia em miastênicos com 


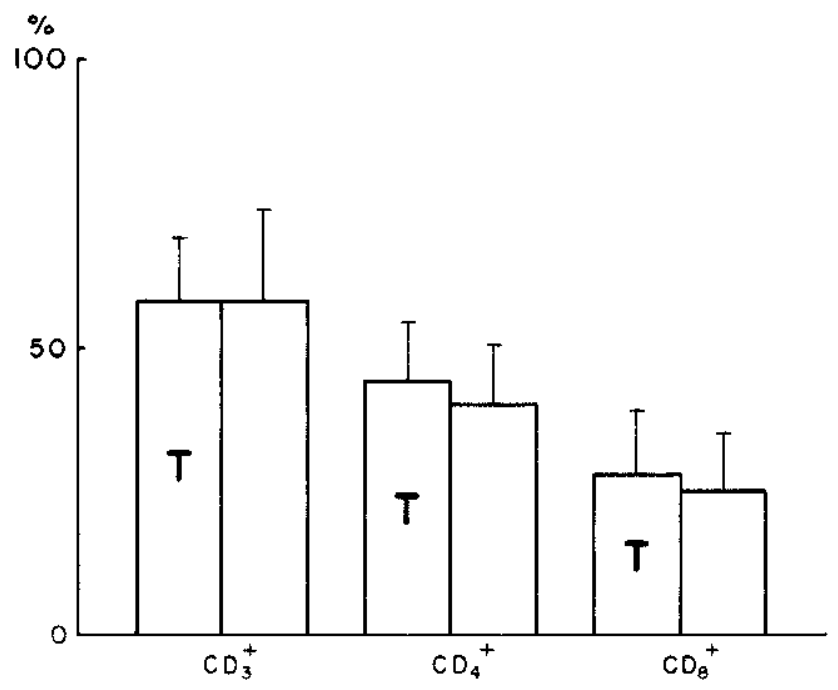

Fig. 3 - Influência da timectomia nas subpopulaçóes de linfócitos na miastenia grave.

timo atrófico, e Miller 16 verificasse elevação dos níveis das células CD4+. As células indiferenciadas não mostraram diferenças estatisticamente significantes em relação aos controles, segundo a técnica e os achados de Berrih 3 que encontrou CD4+ e CD8+ elevados, que se reduziram após a timectomia, embora supomos que a técnica utilizada expresse células inespecíficas e a ausência de controles adequados comprometam os resultados.

Năo encontramos flutuaçōes estatisticamente significantes nos subgrupos de linfócitos $\mathrm{T}$ nos grupos timectomizados submetidos a corticoterapia e nem em relação a sexo e idade. Verificamos, como Christadoss 5 , elevaçōes significativas nos linfócitos B que podem expressar ativação policlonal de células B na geração de autoanticorpos.

Os achados discordantes e até mesmo conflitantes da imunidade celular na MG podem expressar heterogeneidade e polimorfismo da doença, além da variabilidade entre os grupos considerados nos diferentes estudos 19. Dessa forma, parecem ocorrer de forma unânime modestos desequilibrios das células imunorregulatórias circulantes na MG. Acreditamos que essas variaçōes podem ser epifenômeno ou representar perda seletiva de células imunorregulatórias com repercussão na patogênese da $M G$. $O$ mecanismo intrínseco da disfunção primária que permite a produção de anticorpos contra antigeno ainda não está elucidado. Destarte, queremos crer que mínimas alterações no sistema imunológico, interagindo a fatores humorais podem ser responsáveis pelo desequilibrio na homeostase do indivíduo geneticamente determinado, contribuindo para a gênese da doença.

\section{REFERENCIAS}

1. Abdou NI, Lisak RP, Zweiman B, Abrahamsohn I, Penn A - The thymus in myasthenia gravis: evidence for altered cell populations. $\mathrm{N}$ Engl J Med 291:1271, 197.1.

2. Adner MM, Sherman JD, Isé C, Schwab RS, Dameshek W - An immunologic survey of forty-eight patients with myasthenia gravis. N Engl J Med 271:1327, 1964.

3. Berrin S, Gaud G, Bach MA, Le Brigand H, Binet JP, Bach JF - Evaluation of T cell subsets in myasthenia gravis using anti- $T$ cell monoclonal antibodies. Clin Exper Immunol 45:1, 1981 .

4. Biesecker G, Koffler D - Immunology of myasthenia gravis. Hum Path 14:419, 1983. 
5. Christadoss P, Dauphine $N$, Lindstrom J, Dang H, Fernandes G, Talal $N$ - Deficient $T$ cell mitogen response in murine experimental auto immune myasthenia gravis: a defect in the adherent cell population. Cell Immunol 79:358, 1983.

6. Dosch HM, Shore A - Hypothesis: the role of interleukins in lymphopoiesis are important in autoimmune diseases? J Rheumatol 9:353, 1982.

7. Dropcho EJ, Richman DP, Antel JP, Arnason BGW - Defective mitogenic response in myasthenia gravis and multiple sclerosis. Ann Neurol 11:456, 1982.

8. Duarte AJS, Carpenter C.B, Strom TB - Expression of $T$ cell differentiation antigens and Ia on rat cytotoxic T lymphocytes, J Immunol 128:580, 1982.

9. Haynes BF, Harden EA, Orlanow CW, Eisenbarth GS, Wechsler AS, Hensley LL, Roses $\mathrm{AD}$ - Effect of thymectomy on peripheral lymphocyte subsets in myasthenia gravis: selective effect on $\mathrm{T}$-cell in patients with thymic atrophy. $\mathrm{J}$ Immunol 131:773, 1983.

10. Jerne JK - Towards a network theory of the immune system. Ann Immunol 125:373, 1974.

11. Kamo IL, Furukawa S, Tada A, Mano Y, Iwasaki Y, Furuse $\mathbf{T}$ - Monoclonal antibody to acetylcholine receptor: cell line established from thymus of patients with myasthenia gravis. Science 215:995, 1982.

12. Kuroda $\mathbf{Y}$, Oda $\mathbf{K}$, Neshige $\mathbf{R}$, Shibasaki $\mathbf{H}$ - Exacerbation of myasthenia gravis after removal of a thymoma having a membrane phenotype of suppressor $T$ cells. Ann Neurol 15:400, 1984.

13. Landi G, Galli M, Ciboddo G, Colombo R, Scarlato G - Lymphocyte subpopulations and surface membrane immunoglobulins in myasthenia gravis. $J$ Neurol Neurosurg Psychiat 45:158, 1982.

14. Lisak RP, Zweiman B, Skolnik F, Levinson A, Moskovitz AR, Guerrero F - Thymic lymphocyte subpopulations in myasthenia gravis . Neurology 33:868, 1983.

15. Mendes N, Kopersztych S, Saraiva S, Assis JL - Imunidade celular na miastenia grave. Rev Hosp Clin Fac Med São Paulo 33:272, 1978.

16. Miller AE, Hudson $J$, Tindall RSA - Immune regulation in myasthenia gravis: evidence for in increased suppressor T-cell population. Ann Neurol 12:348, 1982.

17. Newsom-Davis J, Willcox N, Scadding G, Calder L, Vicent A - Anti-acetylcholine receptors antibody synthesis by cultured lymphocytes in myasthenia gravis: thymic and peripheral blood cell interations. Ann NY Acad Sci 377:393, 1981.

18. Scadding GK - The role of the thymus in myasthenia gravis. In Rose FC (ed): Clinical Neuroimmunology, Blackwell, Oxford, 1979, pg 128.

19. Shore A, Limatibul S, Dosch HM, Celfand WW - Identification of two serum components regulating the expression of T-lymphocytes function in childhood myasthenia gravis. N EngI J Med 201:625, 1979.

20. Skolnik PR, Lisak RP, Zweiman B - Monocional antibodty analysis of blood T-cell subsets in myasthenia gravis. Ann Neurol 11:170, 1982. 